\title{
Historia de la cirugía de cadera en el Centro Médico ABC
}

\section{Hip surgery in the ABC Medical Center}

\author{
Javier Camacho-Galindo*
}

Citar como: Camacho-Galindo J. Historia de la cirugía de cadera en el Centro Médico ABC. An Med ABC. $2021 ; 66$ (2): $151-155$. https://dx.doi.org/10.35366/100487

\section{RESUMEN}

La historia de la cirugía de cadera en el Centro Médico ABC inició desde su creación en 1941. Una gran cantidad de distinguidos cirujanos ortopedistas han practicado en todos estos años en nuestro hospital. Uno de los más sobresalientes fue el Dr. Marco Antonio Lazcano, quien realizó la primera prótesis de cadera de baja fricción tipo Charnley en el Centro Médico ABC. En los años subsiguientes, llevó a varios cirujanos dedicados a la cirugía de cadera a evolucionar y traer diversas técnicas, hasta lo que el día de hoy se realiza, una cirugía de alto nivel que se encuentra en los estándares de muchos otros centros del país y del mundo.

Palabras clave: Historia, cirugía de cadera, artroplastia de cadera.

\section{CIRUGÍA DE CADERA EN EL CENTRO MÉDICO ABC}

La historia de la cirugía de cadera en el Centro Médico ABC inició justo con la unión del Hospital Americano y del Sanatorio Cowdray en 1941, en la que distinguidos cirujanos ortopedistas trataban las fracturas de cadera y algunos padecimientos de

\footnotetext{
* Cirujano Ortopedista, Centro de Ortopedia y Traumatología del Centro Médico ABC. Ciudad de México.
}

Recibido: 05/05/2021. Aceptado: 09/06/2021.

Correspondencia:

Dr. Javier Camacho Galindo

E-mail: jvrcamacho@hotmail.com

\begin{abstract}
The beginning of the hip surgery history started with the creation of the ABC Medical Center in 1941. Several distinguish orthopedic surgeons has been practice during these years in our hospital. Dr. Marco Antonio Lazcano has been one of the outstanding surgeons. He performed the first Charnley low friction hip replacement in the $A B C$ Medical Center. In the following years, the hip surgeons improved the techniques in treatment. Today, the hip surgery in the ABC Medical Center is a high standard practice that could be compared with another center in the Mexico as well in another countries.
\end{abstract}

Keywords: History, hip surgery, hip arthroplasty.

esta articulación. Entonces las fracturas de cadera se trataban con osteosíntesis de manera abierta a través del abordaje lateral, utilizando las placas de McLaughlin con clavo de Smith Petersen o la placa clavo de Jewett, así como tornillos de acero inoxidable y clavos como el de Küntscher; en el caso de fracturas intraarticulares subcapitales, inicialmente se trataban con la prótesis de Austin Moore y más tarde con la de Thompson; las artrosis se trataban con copa de Smith Petersen. Con estos mismos dispositivos se fijaban las osteotomías alineadoras de cadera, con el fin de reducir el dolor en aquellos casos en que el desgaste era el causante (Figuras 1 a 3).,1,2

Fue hasta 1970 cuando el Dr. Marco Antonio Lazcano, entonces alumno del Dr. Charnley, colocó la primera prótesis de cadera cementada en el Centro Médico ABC, así como en el Instituto Nacional de la 
Nutrición, de aquí fue seguido por varios cirujanos ortopedistas, siendo este implante uno de los más utilizados en los años 70 y 80 en nuestro hospital, debido a la rápida fijación de los implantes con el invento del maestro Charnley, el cemento de hueso (polimetilmetacrilato [PMMA]), mismo conocimiento que plasmó en 1984 en el libro llamado Artroplastia

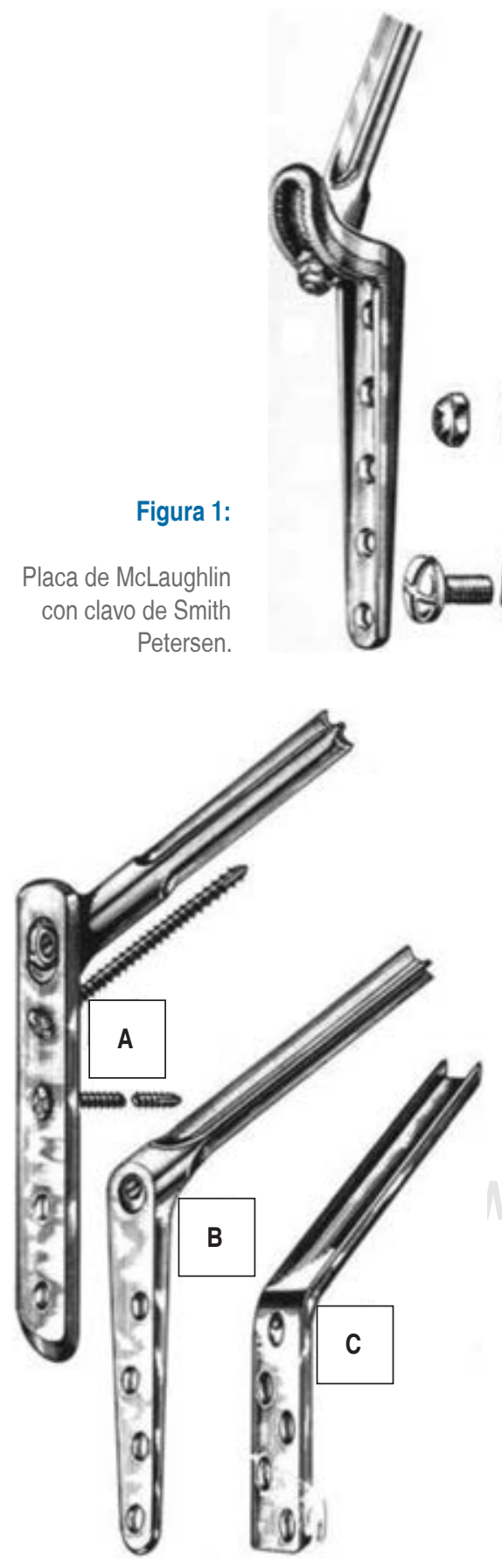

Figura 2:

Placas: A) Staca, B) clavo placa de Jewett y C) Müller.
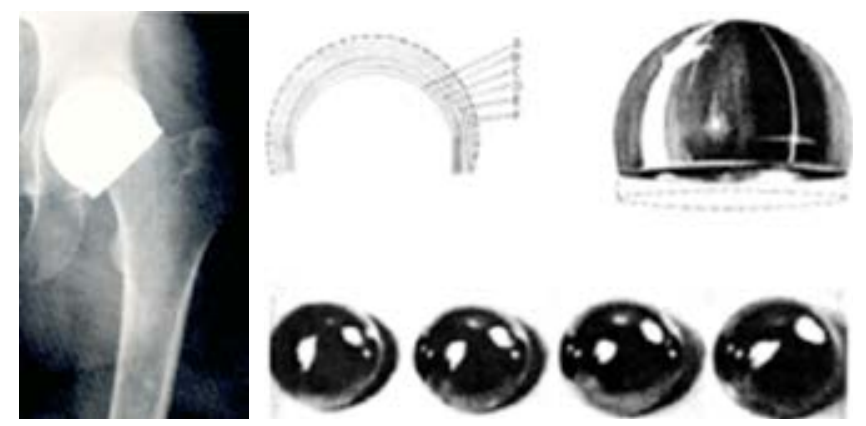

Figura 3: Cúpula de Smith Petersen.

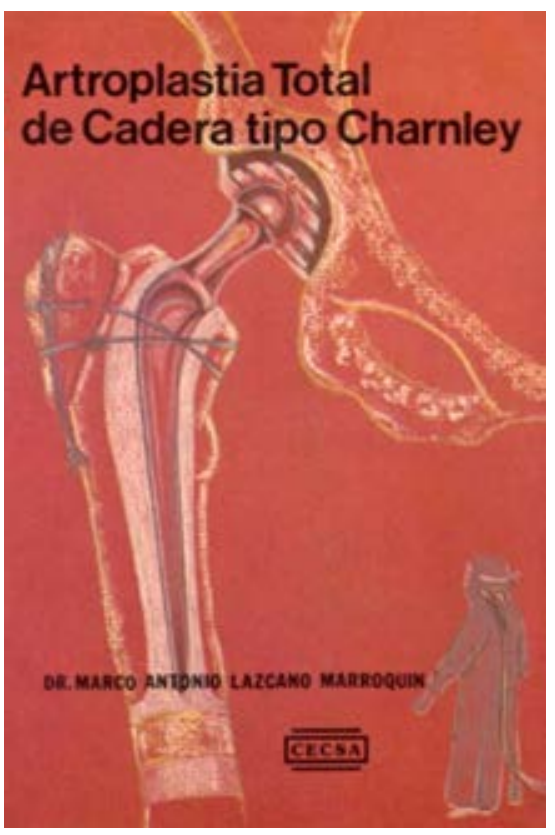

Figura 4:

Libro Artroplastia total de cadera tipo Charnley, 1984.

total de cadera tipo Charnley que mencionaba recomendaciones, técnica y conceptos importantes sobre la cadera y las prótesis de baja fricción, con el objetivo de convertir al Hospital $\mathrm{ABC}$ en un centro de reemplazos de Charnley, así como difundir el conocimiento a toda Latinoamérica. Esta publicación se realizó gracias a un donativo importante por parte del entonces Hospital ABC (Figura 4). 1,3

Asimismo, el Dr. Lazcano en el Centro Médico $\mathrm{ABC}$, consciente del problema de las infecciones y las prótesis de cadera, dio la pauta para colocar en septiembre de 1973 la primera sala estéril del país con con el apoyo del Lic. Raúl Alvarado, ex director del hospital, así como del Dr. Salvador Zubirán. Esta sala llamada tipo Charnley-Howorth consistía en un recinto cerrado con paredes de plástico, en la parte su- 

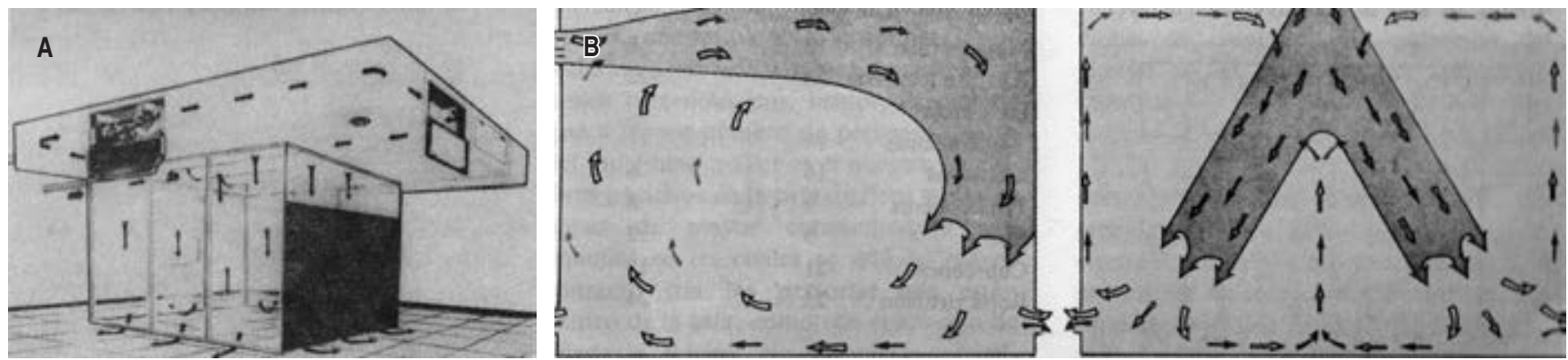

Figura 5: A) Sala de operaciones tipo Charnley-Howorth. B) Sala común dirección de las salidas de aire. ${ }^{4}$

perior tenía un sistema de ventilación que filtraba el aire con prefiltros y filtros bacteriológicos HEPA que eliminaban el polvo y bacterias de más de 3 micras. De esta forma, el aire filtrado salía del techo de la sala estéril hacia el suelo sin producir corrientes de convección a una velocidad de $60 \mathrm{pies} / \mathrm{min}$ y 300 cambios de aire por hora. Esta era la sala 2 de observatorio, que por mucho tiempo mantuvo las adaptaciones realizadas para estos fines y donde se realizaron miles de cirugías ortopédicas, utilizada por muchos de nosotros. En este tema, también implementó en el hospital el uso de las batas impermeables con casco visor, las que cubrían el cuerpo de cabeza hasta los tobillos, el casco visor tenía un sistema de succión por medio de tubos colocados a los lados de la cara y que extraían la espiración contaminada de la nariz y boca del cirujano, quedando así controladas las principales fuentes de contaminación dentro del quirófano (Figuras 5 y 6 ): ${ }^{4}$

1. Las vías aerógenas con el polvo.

2. Las partículas de descamación de la piel del cirujano y ayudantes.

3. Las bacterias de la nasofaringe del cirujano.

En la misma época desarrolló un implante monopolar cementado basado en el diseño del vástago recto de Charnley, con el fin de facilitar el tratamiento de las fracturas de cadera intracapsulares en pacientes de tallas mexicanas. De este implante obtuvo el
Hemiartroplastia de

cadera tipo Lazcano para

fracturas intertrocantéricas

Figura 6:

Bata impermeable con casco visor. ${ }^{4}$

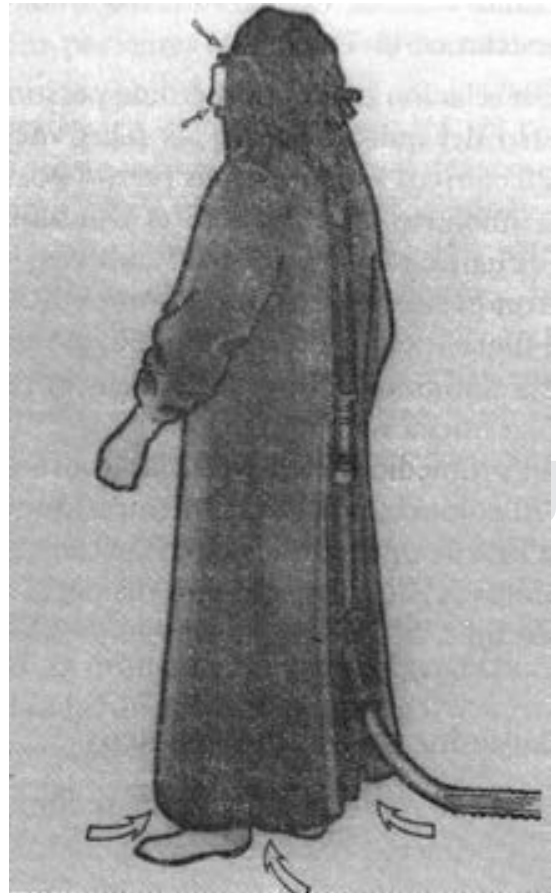

Figura 7:

Tercera publicación del Dr. Lazcano. 

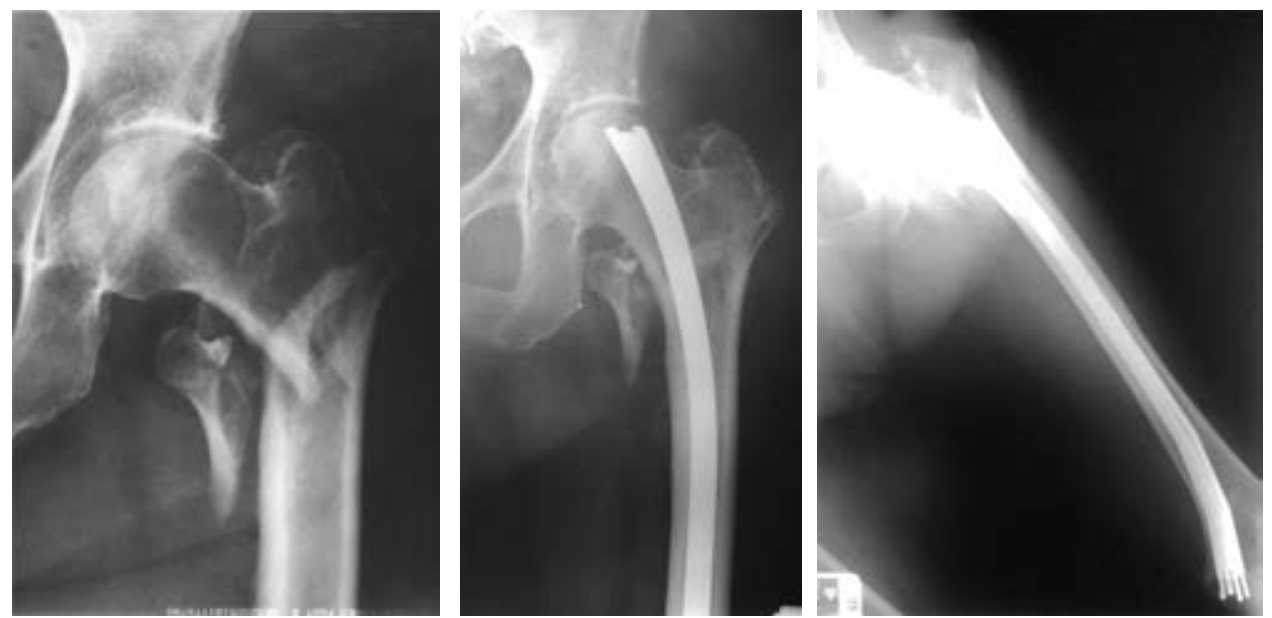

Figura 8:

Clavos de Ender (cortesía del Dr. Antonio Velutini K). título de registro de modelo industrial en 1993, llamándole prótesis tipo Lazcano; más tarde le agregó al diseño un cuello con el que propuso este implante para el tratamiento de las fracturas extracapsulares, dedicándole a este implante dos libros. A la fecha, aún se produce este modelo con el concepto que entonces tenía el Dr. Lazcano, un implante de fácil colocación, de costo accesible y buena función (Figura 7).

Algunos cirujanos, como el Dr. Holshneider y el Dr. Velutini también en los 70, prefirieron la tecnología europea colocando la prótesis cementada de Charnley-Müller, que utilizaba un vástago curvo no cementado con copa de polietileno con resultados muy similares a los de la famosa prótesis de baja fricción de Charnley. Con el fin de demostrar que este implante de cadera era confiable, el Dr. Buchholz, otro profesor de cadera ampliamente conocido por todos, fue invitado al Hospital ABC donde realizó algunas artroplastias, además de dar unas pláticas sobre la experiencia de la ENDO-Klinik de Hamburgo.

El tratamiento de las fracturas fue evolucionando con placas más sofisticadas como el sistema de tornillo condilar (DCS) y más tarde el sistema dinámico de cadera (DHS) creado en Suiza. Los clavos de Ender, que hicieron su aparición en 1972, fueron otra opción empleada por el Dr. Velutini a su regreso de Alemania en 1977 para el tratamiento de las fracturas del extremo proximal de fémur, basado en el principio de elasticidad y su montaje multifasciculado desde un abordaje mínimo en el extremo distal del fémur sobre el cóndilo medial, rellenando el canal medular de modo de «maza de puros», obteniendo un excelente resultado (Figura 8).

En los años 90, el reemplazo total de cadera y las prótesis que originalmente se insertaban con cemento óseo y fallaban en el 10 a $15 \%$ de los casos dentro de los 10 a 15 años como consecuencia del gradual deterioro y pérdida de contacto del cemento, con consecuente aumento de dolor y obligando a una revisión del reemplazo de cadera, la cual era un procedimiento complejo con pocas opciones de dispositivos para emplear, evolucionaron con el uso de prótesis de cadera no cementada, siendo de los primeros cirujanos en utilizarlo en el Centro Médico ABC el Dr. Nelson Cassis, el Dr. Gómez Amezcua y el Dr. Marcial, colocando la famosa hasta la fecha pero ya en vías de desaparición prótesis de Mallory Head, la que entonces era una de las representantes de las aleaciones de titanio, presentando excelentes porcentajes de sobrevida a 15 años.

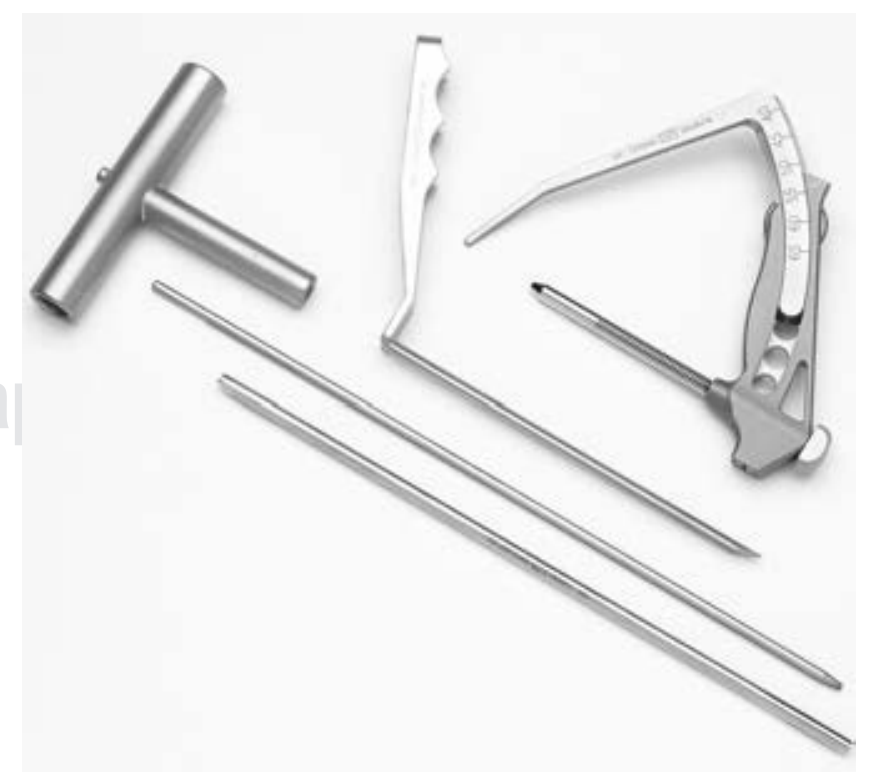

Figura 9: Instrumental especial de artroscopia de cadera. ${ }^{5}$ 
En la actualidad se realizan una gran diversidad de cirugías de cadera, desde luego está el reemplazo de cadera total primario y de revisión, tratamiento de fracturas con diversos materiales de osteosíntesis como clavos, placas y tornillos; cirugía preservadora de cadera como osteotomías periacetabulares, luxaciones abiertas controladas, osteotomías femorales y artroscopia de cadera; de esta última, a finales de los 90 se hicieron un par de artroscopias con el diagnóstico de cuerpos extraños intraarticulares, realizándose con el instrumental de hombro y rodilla. Fue hasta el 2006 que se realizó en el Centro Médico ABC, por el Dr. Javier Camacho, la primera artroscopia de cadera moderna con el diagnóstico de ruptura labral, con tracción en posición lateral con instrumental especialmente diseñado para el acceso a la articulación (Figura 9). ${ }^{5}$

Todas estas técnicas que se realizan en el Centro Médico $\mathrm{ABC}$ son cirugías que se utilizan en otras instituciones del país, así como del mundo, y están muy cercanas a los estándares que se manejan en dichos centros. Eventualmente la tecnología seguirá evolucionando, lo que sigue es la cirugía robótica y técnicas nuevas mejoradas con los ins- trumentales y accesorios para realizarla, sin duda el Centro médico ABC tendrá la capacidad de ofrecer esta tecnología de punta.

\section{AGRADECIMIENTOS}

Agradezco al Dr. Juan Manuel Fernández V, Dr. Nelson Cassis y Dr. José Antonio Velutini K el tiempo para realizar esta historia.

\section{REFERENCIAS}

1. Fernández VJM, Camacho GJ, Álvarez SFS. La ortopedia y traumatología en el Centro Médico ABC: historia. An Med Asoc Med Hosp ABC. 2017; 62 (1): 74-79.

2. Sueiro-Fernández J, Ballester-Alfaro JJ, Ayerbe-Zubimendi P, Torres-Pérez A. Evolución histórica de las ideas en el tratamiento de fracturas trocantéricas. Rev S And Traum y Ort. 2013; 30 (2/2): 19-27.

3. Fernández VJM, Camacho GJ. Dr. Marco Antonio Lazcano Marroquín 1930-2006. Acta Ortop Mex. 2009; 23 (2): 112-114.

4. Lazcano MA. Artroplastia total de cadera tipo Charnley. México, D.F.: Ed. Cecsa; 1984.

5. Ilizaliturri VM, Chaidez PA, Aguilera JM, Camacho-Galindo J. Special instruments and techniques for hip arthroscopy. Tech Orthop. 2005; 20 (1): 9-16. 